\title{
Habits as the basic global medicine
}

\section{Diego Liberati* \\ National Research Council of Italy, Italy}

When we think about medicine we immediately recall drugs and need to heal when ill. Global medicine is first prevention, and mostly habits. An old story reminded that in traditional Chinese medicine the physician is paid until one is healthy, stopping when ill until health is regained!

We are mostly water, and we mostly live on breath, every few seconds. A good habit in breathing, both in term of quality of air (no smoking at least!) and rhythm (respiration controls parasympathetic activity able to relax) are already a great deal for our health. Air and water pollution are the most direct and heavy threats to our health!
This does not mean that drug is unuseful, not are physical therapies, both in acute and chronical needs: just, these are powerful weapons to be carefully used when really needed, not forgetting the basic attitude of good breathing, drinking, eating and sleeping, as much as possible.

The ultimate dream for global medicine thus is not the magical pill healing everything, obviously just a dream, but the wiseness to take advantage from simple things daily.
Copyright: (C2018 Liberati D. This is an open-access article distributed under the terms of the Creative Commons Attribution License, which permits unrestricted use, distribution, and reproduction in any medium, provided the original author and source are credited.
${ }^{\star}$ Correspondence to: Diego Liberati, National Research Council of Italy, Italy, Tel: +393480569317; E-mail: diego.liberati@gmail.com

Received: May 21, 2018; Accepted: June 01, 2018; Published: June 07, 2018 